\title{
Ebola virus disease epidemic in West Africa: lessons learned and issues arising from West African countries
}

\author{
Authors: Obinna O Oleribe, ${ }^{\mathrm{A}}$ Babatunde L Salako, ${ }^{\mathrm{B}} \mathrm{M}$ Mourtalla Ka, ${ }^{\mathrm{C}}$ Albert Akpalu, ${ }^{\mathrm{D}}$ Mairi McConnochie, ${ }^{\mathrm{E}}$ Matthew \\ Foster $^{\mathrm{F}}$ and Simon D Taylor-Robinson ${ }^{\mathrm{G}}$
}

\begin{abstract}
The current Ebola virus disease (EVD) outbreak ravaging three nations in West Africa has affected more than 14,000 persons and killed over 5,000. It is the longest and most widely spread Ebola epidemic ever seen. At the time of this overview (written November 2014), having affected eight different nations, Nigeria and Senegal were able to control and eliminate the virus within a record time. Ghana has successfully, to date, kept the virus away from the country, despite economic and social relationships with affected nations. What lessons can we learn from Nigeria, Senegal and Ghana in the current epidemic? How can the world improve the health systems in low- and middle-income countries to effectively manage future outbreaks? Recently, the Royal College of Physicians launched a new partnership with the West African College of Physicians to curtail the effects of HIVIAIDS, malaria and tuberculosis in the region. We believe that strengthened health systems, skilled human resources for health and national ownership of problems are key to effective management of outbreaks such as EVD.
\end{abstract}

KEYWORDS: Ebola, West Africa, Nigeria, Ghana, Senegal

\section{Introduction}

The ongoing Ebola virus disease (EVD) epidemic that began approximately 10 months ago in the Republic of Guinea

Authors: ${ }^{A}$ West African project coordinator, WACP/RCP M-PACT Project/chief executive officer, Excellence and Friends Management Care Centre, Abuja, Nigeria; ${ }^{B}$ national course convener, WACP/RCP M-PACT Project (Nigeria), Provost College of Medicine, University of Ibadan, Ibadan, Nigeria; ' national course convenor, WACP/RCP M-PACT Project (Senegal)/Centre Hospitalier Regional de Thies et UFR des Sciences de la Santé

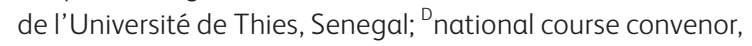
WACP/RCP M-PACT Project (Ghana), Department of Medicine, Korle Bu Teaching Hospital, Accra, Ghana; ${ }^{\text {Ehead of international }}$ affairs, International Office, Royal College of Physicians, London, UK; ${ }^{F}$ director of engagement and international partnerships, International Office, Royal College of Physicians, London, UK; ${ }^{G}$ associate international director for Africa, Royal College of Physicians, London, UK
(Guinea-Conakry), ${ }^{1}$ was declared by the World Health Organization (WHO) as a 'public health emergency of international concern' on 8 August 2014. Since 23 March 2014, when the WHO was first notified, EVD has affected (as at 14 November 2014) 14,413 individuals in eight different nations, with 5,177 deaths and a case fatality rate (CFR) of $35.92 \% .^{2,3}$

The West African EVD outbreak is different from the 2014 Ebola outbreak in the Democratic Republic of the Congo (DRC) with 66 cases ( 38 confirmed, 28 probable and 49 deaths), including 8 among healthcare workers (HCWs), and a higher CFR of $74.24 \%{ }^{4}$

The current Ebola outbreak in West Africa is very unusual, and has almost completely reversed developmental gains in Liberia, Guinea and Sierra Leone following their civil wars. ${ }^{5}$ According to WHO situation reports, case incidence has continued to increase in Sierra Leone, and transmission remains intense in Guinea and Liberia, affecting all districts of the two countries. The largest number of cases has been seen in Liberia (6,878 cases with 2,812 deaths, $40.88 \%$ CFR), followed by Sierra Leone ( 5,586 cases with 1,187 deaths, $21.45 \%$ CFR) and Guinea (1,919 cases with 1,166 deaths, $60.76 \%$ CFR). Other affected nations are Nigeria (20 cases with 8 deaths, $40.0 \%$ CFR), Mali (4 cases with 3 deaths, $75.0 \%$ CFR), Senegal and Spain (one case each with no death, $0 \%$ CFR) and USA ( 5 cases with 2 deaths, $40.0 \%$ CFR). ${ }^{2}$ This shows different levels of infection, as well as mortality, across the affected nations.

There have been previous outbreaks of EVD in West Africa. In 1976, the first case was identified with two concurrent outbreaks involving 284 cases with 151 deaths (53.0\% CFR) in Sudan, and 318 cases with 280 deaths (88.0\% CFR) in DRC. ${ }^{6}$ There have been roughly 23 other outbreaks occurring through to 2013, involving nearly 2,500 cases, mostly in the East and Central African countries of DRC, Sudan, Gabon, Ivory Coast, Uganda and Congo-Brazzaville. ${ }^{6,7}$

However, the current outbreak is characterised by a much larger epidemic and rapid spread, mainly among West African nations that are not themselves prepared for the outbreak. By contrast, the previous outbreak in the Ivory Coast in 1994 only involved a single case. ${ }^{7}$

Although the current epidemic began late in December 2013, it was not until March 2014 that it was first reported to the WHO. ${ }^{8}$ Delayed identification catalysed the rapid spread of the epidemic. Poor management of cases and ineffective outbreak responses, resulting from weak health systems in countries 
previously riven by civil war, with inadequate healthcare personnel and ineffective healthcare funding systems, further fuelled the epidemic, especially in the most affected countries. Unlike previous outbreaks of EVD, the current massive epidemic was further stimulated by chains of secondary spread within family units, involvement of more urban areas, care of the majority of cases in hospitals or at home by HCWs who do not have access to proper protective equipment, African rituals of washing deceased bodies before burial, and the social habits of hand shaking and hugging. ${ }^{9}$

When the epidemic entered Nigeria, there were fears that the large population of Lagos, poor health systems, Nigerian cultures and doctors' strikes would fuel the epidemic and make Nigeria a worse case than other African nations. However, with just 20 cases and eight deaths, Nigeria (20 October 2014) and Senegal (17 October 2014) were declared Ebola free by the WHO. ${ }^{10,11}$ The DRC may also be declared Ebola free soon, if no new cases are reported. ${ }^{2}$

While the world celebrates these achievements, a number of issues and lessons have arisen from this ongoing epidemic: poor preparation of health systems for major epidemics, an absence of functional global surveillance systems, weak health systems, unprepared and unskilled HCWs, and poor access to and knowledge of the use of personal protective equipment. In addition, the devastating effects of culture, hand-washing habits, social media and religious practices have all been clearly demonstrated in the recent outbreaks.

Since 1979 when the world agreed to pursue the 'Health for All' dream, and 2000 when the Millennium Development Goals (MDGs) were accepted as global targets, there have been encouraging gains in the health outcomes of nations. Notably, Liberia has experienced impressive gains in life expectancy and health services. ${ }^{12-16}$

However, the gains of 'Health for All' and MDGs in health outcomes and health systems have all been reversed by the current prolonged and devastating EVD outbreak. The Royal College of Physicians (RCP) and West African College of Physicians (WACP) recently launched the MDG6 Partnership for African Clinical Training (M-PACT) (funded by the ECObank Foundation), towards the achievement of MDG6 combatting HIV/AIDS, malaria and other diseases. Initiatives such as these cannot succeed without functional and reliable health systems.

\section{The Nigerian national response}

The first case of Ebola entered Nigeria through a commercial airline on 20 July 2014, transporting a diplomat, Patrick Sawyer, from Liberia to Nigeria. ${ }^{10}$ Diagnosis was suspected on 23 July 2014 and confirmed on 25 July 2014, the day that the patient died.

Following this diagnosis, the Federal Ministry of Health (FMOH), the Nigerian Center for Disease Control (NCDC) and the Nigeria Field Epidemiology and Laboratory Training Program (NFELTP) were mobilised to investigate, manage and control the epidemic - with support from the Lagos State Government. This reactive and prompt response was instrumental to the tracking, quarantine and management of contacts in Lagos.

In spite of this state-wide effort, the disease eventually spread to Port Harcourt, a city in the South of the country, via an individual on surveillance who came to the city to seek private (and secret) treatment, perhaps fearing stigmatisation. The doctor who treated this individual eventually contracted the disease and died while the patient survived, following a very brief illness.

By 26 September 2014, there were 20 cases in Nigeria (19 confirmed and 1 probable), with eight deaths (seven confirmed and one probable) and a national CFR of $40.0 \%$ (Lagos, $37.5 \%$ and Port Harcourt, 50.0\%). The majority of the affected people were HCWs (16 with 5 deaths and $31.23 \%$ CFR). ${ }^{17}$

In addition to Lagos and Port Harcourt, there were suspected cased in Abuja, Ibadan and Ille Ife where there were documented episodes of 'Ebola scare'. 18

The success of the national response can be linked to the prior establishment of the Integrated Disease Surveillance and Response Program in 1998, the NFELTP in 2008, and NCDC in 2012, as well as the responsiveness of the Lagos State Ministry of Health. Previous Nigerian experience in the management of Lassa Fever, another viral haemorrhagic infection, also helped 'nip the epidemic in the bud'. To keep the virus out of Nigeria, the Port Health services, which were previously ill prepared, responded rapidly as they started monitoring all national entry points (land, sea and air) and examined all who were entering or leaving the country through infra-red temperature checks. In addition, hand washing was emphasised and use of sanitisers publicised.

As part of the control measures in Nigeria, there was a massive mobilisation, awareness creation and sensitisation of the populace to the dangers, signs and symptoms of EVD, and acceptable practices within and outside the health institutions. This led to a delay in school resumption and shortening of the duration of national camping programmes, such as the National Youth Service Corps. The immediate response by Nigeria to keep the virus at bay completely nullified the mathematical models by averting hundreds of thousands of new cases. Although it was predicted that without drastic improvements in control measures, the numbers of cases of and deaths from EVD would increase from hundreds to thousands per week, this prediction failed to materialise. ${ }^{3} \mathrm{~A}$ local, immediate, and culturally sensitive response is therefore vital for timely control of epidemics. Support from outside is of course highly desirable, but if local capacity and resources are properly mobilised and channelled, external support may arrive when disease outbreaks are already contained, like in Nigeria. ${ }^{19}$

\section{Effect on the Nigerian health system}

The Nigerian health system, though able to curtail the spread, was not prepared for the epidemic, despite the news of the disease in neighboring countries. For instance, the doctors were on industrial action. In addition, it took five days before the first diagnosis could be made. However, volunteer HCWs were available to assist in the management of the disease in both cities of Lagos and Port Harcourt with NFELTP residents deployed to the field for contact tracing, monitoring and isolating of cases. The majority of those that contracted the disease were HCWs (11 cases, 55\%). To curtail the epidemic, funds for other health system activities were re-routed to combat EVD epidemics, at the expense of other health issues. Isolation and quarantine centres were set up in Lagos, Port Harcourt and several regional centres including the University College Hospital, Ibadan (Fig 1). Major government hospitals were instructed to form an 'Ebola Response Team'. 


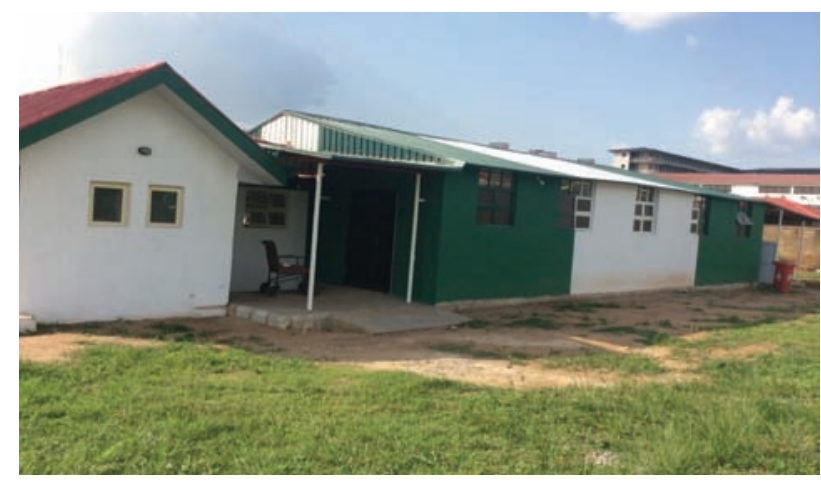

Fig 1. Prototype of an isolation and quarantine centre, University College Hospital, Ibadan, Nigeria.

Daily coordination meetings were held at the Ebola Emergency Operations Center to document activities, review preparedness plans and monitor isolation centre activities. Supervisory visits were paid to HCWs in the field.

\section{‘Ebola scare'}

One thing that became obvious following the extensive awareness campaign was a phenomenon that can be rightly described as 'Ebola scare', an episode that played out in Abuja, Ibadan and Ife-Ife, where suspected cases were encountered (Fig 2). ${ }^{18}$ Patients in various places presented with symptoms similar to that of EVD. HCWs were scared and in some cases became apprehensive about becoming carriers of EVD.

Rumours of the disease spread throughout the affected cities. Sometimes HCWs and would-be hospital patients were known to desert the hospital. The situations were reversed as soon as the patients tested negative to the virus, but these results could take 5-7 days. ${ }^{18}$

\section{The Senegal national response}

The only case of Ebola in Senegal was a student from GuineaConakry who travelled to Senegal. When he was found to be symptomatic with diarrhoea, fever and other symptoms, he was seen in a suburban medical centre and was treated for malaria.

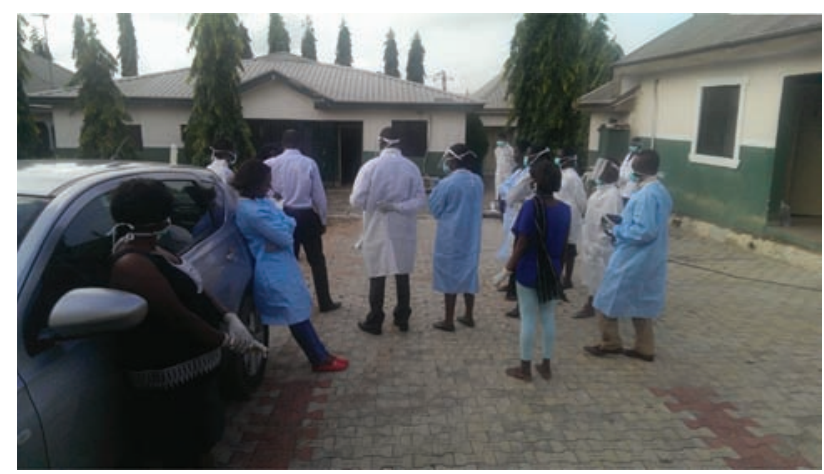

Fig 2. Staff and relations of a hospital in Abuja, Nigeria with 'Ebola scare' in September 2014.
He was then seen at the University Hospital in Dakar, where the diagnosis of Ebola was made on 29 August 2014, and he was treated. ${ }^{20}$

At the national level, there are a number of teams activated to monitor for fever. All those that came in contact with the index case were monitored in their houses on a daily basis. In total, more than 67 close contacts of the initial case were identified and monitored twice daily, five contacts who developed Ebolalike symptoms were tested and found negative. ${ }^{20}$

Six months before the case, there had been extensive educational activity all over Senegal and unlike Nigeria, the country was ready for the epidemic before the first case was seen. The Senegal epidemic benefited from the presence of an Institut Pasteur laboratory in Dakar, a WHO-approved collaborating centre with excellent facilities and staff, where the initial case was identified. ${ }^{20}$ Their extensive experience in EVD and the related Marburg haemorrhagic fever ensured immediate control and eradication of the virus from the country.

To ensure that Ebola is kept out of Senegal, the government has given mobile phones to the regions not far from GuineaConakry with a toll-free number, which anybody can call if there are suspects. The government also mobilised the national ambulance service, which handles every emergency, to be part of the Ebola control process.

\section{The Ghana national response}

Ghana, like Nigeria, does not have a direct boundary with the three most affected nations, but unlike Nigeria, it has remained Ebola free due to a interministerial supervisory effort of Port Health, immigration, security services and the Ghana Health Service, as well as national and regional technical coordinating committees and public health sensitisation efforts.

Three Ebola treatment centres were set up to manage cases. They were charged with surveillance, situation monitoring and assessment; case management; health education, social mobilisation and risk communication; logistics, security and financial resources; and planning and coordination. The approved insurance package for frontline health staff working on Ebola prevention and control by the government was another positive step. ${ }^{21}$

To keep Ebola out of Ghana, the government instituted education and training across the health and social divide; created awareness in the media, churches, schools and public places; and encouraged prevention measures of hand washing, avoiding unnecessary physical contact with ill people, changing burial procedures and increased surveillance/screening at the ports. Further, the Government of Ghana facilitated the establishment of the United Nations' (UN) Ebola response mission in Africa (United Nations Mission for Ebola Emergency Response) to be headquartered in Ghana.

\section{Preparing for future outbreaks}

Current lessons learned from the ongoing outbreak should be institutionalised. The countries of West Africa certainly need to be well prepared for possible future epidemics. They need to learn also from their current experience, just as Nigeria was able to use the previous experience and structure in handling Lassa fever outbreaks as a model to combat the Ebola virus epidemic. Strong health systems with a robust public health 
component have to be put in place. Western countries like the USA, UK and France need to show leadership in the area of investigational treatment plans, while also building capacity in Africa generally in the area of viral haemorrhagic fevers.

The UN and WHO, as major health organisations, have to give direction in team building, international surveillance system structures and effective vaccination plans. Funding for research should also be made available to study survivors and define the factors that can mitigate the spread of the disease. They should also show leadership by providing templates for the use of investigational drugs and the ethics relating to management of severe clinically infective cases in intensive care units and dialysis centres, and the use of respirators.

Robust awareness campaigns both locally and internationally will help to improve communication across several countries at risk. More importantly, countries of West Africa have to engage the public on a continuous basis to publicise and effect a preventive strategy against EVD. In addition, the RCP/ WACP MDG6 M-PACT project will further improve capacity and leadership to manage current and future epidemics and outbreaks in the subregion.

\section{Conclusion}

Although the outbreak is still ongoing in Liberia, Guinea and Sierra Leone, there are indications that the epidemic is subsiding. ${ }^{2}$ Lessons learnt from Nigeria, Senegal and Ghana can be fed into the control process to further reduce the devastation of this epidemic. The excellent role of local skilled manpower, as seen in Nigeria, calls for a more effective development of human resources for future outbreaks. The role of institutions such as the NFELTP, NCDC and Lagos State Government shows the relevance of focused institutions in the management of health hazards. Continued support of the most affected nations by the USA, UK and France will prevent similar outbreaks by funding the establishment of national field epidemiology and laboratory training programmes in these nations. The current partnership between RCP and WACP is a step in the right direction. When the proposed centres are up and running, they will help build capable HCWs who, among several other things, will be useful in the prevention and control of outbreaks such as EVD.

Finally, the gains of the outbreak, such as improved Port Health services, public health activities in Nigeria, handwashing practices and burial practices should be strengthened and institutionalised.

\section{Acknowledgements}

The authors acknowledge Prof Jane Dacre, president of the Royal College of Physicians, for the initial idea to develop this manuscript. We also thank Prof M Lartey (Ghana) and Dr Janice Main (Imperial College, London, UK) for additional information on Ebola prevention.

\section{Declarations}

All authors are involved in delivering the joint RCP-WACP M-PACT educational programme on TB, HIV, malaria and disease outbreak management in West Africa in 2015.

\section{References}

1 Dixon MG, Schafer IJ. Ebola viral disease outbreak - West Africa, 2014. MMWR Morb Mortal Wkly Rep 2014;63,548-51.
2 WHO (2014). Ebola response roadmap - Situation report update. Global Alert and Response, 3 December 2014. Available online at www.who.int/csr/disease/ebola/situation-reports/en/ [Accessed 18 November 2014].

3 WHO Ebola Response Team (2014). Ebola virus disease in West Africa - the first 9 months of the epidemic and forward projections. N Engl J Med 2014;371:1481-95.

4 Maganga GD, Kapetshi J, Berthet $\mathrm{N}$ et al. Ebola virus disease in the Democratic Republic of Congo. N Engl J Med 2014;371:2083-91.

5 Salako BL, Ka M, Akpalu A, Oleribe O, Taylor-Robinson S. The Ebola outbreak in West Africa: lessons learned from West African countries. Ebola guidance, 29 October 2014. Available online at www.rcplondon. ac.uk/update/ebola-guidance [Accessed 18 November 2014].

6 Laupland KB, Valiquette L. Ebola virus disease. Can J Infect Dis Med Microbiol 2014;25:128.

7 Elisha A, Adegboro B. Ebola virus diseases. Afr J Clin Exp Microbiol 2014;15:117-21.

8 Nishiura H, Chowell G. Early transmission dynamics of Ebola virus disease (EVD), West Africa, March to August 2014. Euro Surveill 2014;19:20894.

9 Baron RC, McCormick JB, Zubeir OA. Ebola virus disease in southern Sudan: hospital dissemination and intrafamilial spread. Bull World Health Organ 1983;61:997-1003.

10 WHO. WHO declares end of Ebola outbreak in Nigeria. Media Centre statement, 20 October 2014. Available online at www.who. int/mediacentre/news/statements/2014/nigeria-ends-ebola/en/ [Accessed 19 November 2014].

11 WHO (2014). WHO congratulates Senegal on ending Ebola transmission. Media Centre statement, 17 October 2014. Available online at www.who.int/mediacentre/news/statements/2014/senegal-endsebola/en/ [Accessed 19 November 2014].

12 Easterly W. How the millennium development goals are unfair to Africa. World Dev 2009;37:26-35.

13 Sachs JD, McArthur JW. The millennium project: a plan for meeting the millennium development goals. Lancet 2005;365:347-53.

14 TO A. Health for all beyond 2000: the demise of the Alma-Ata Declaration and primary health care in developing countries. Med J Aust 2003;178:17-20.

15 Travis P, Bennett S, Haines A et al. Overcoming health-systems constraints to achieve the Millennium Development Goals. Lancet 2004;364:900-6.

16 Walley J, Lawn JE, Tinker A et al. Primary health care: making Alma-Ata a reality. Lancet 2008;372:1001-7.

17 FMOH (2014). Ebola virus disease outbreak in Nigeria. Daily Situation Report no 58, 26 September 2014.

18 Oleribe O, Oladipo O, Nwachukwu C, Abimbola A, and Nwanyanwu O. The complicated and complex Ebola Viral Disease (EVD) in West Africa. AASCIT 2014;1:2375-3803

19 Pailey R. Nigeria, Ebola and the myth of white saviours. Aljazeera, 8 November 2014. Available online at www.aljazeera.com/ indepth/opinion/2014/11/nigeria-ebola-myth-white-saviours201411654947478.html\#.VGII3Xn0rdU.facebook [Accessed 18 November 2014].

20 WHO. Ebola situation in Senegal remains stable. Media Centre situation assessment, 12 September 2014. Available online at www. who.int/mediacentre/news/ebola/12-september-2014/en/ [Accessed 19 November 2014].

21 Ghana Web. US lauds Ghana's Ebola preparedness plan. General News of Thursday, 30 October 2014. Available online at www.ghanaweb.com/GhanaHomePage/NewsArchive/artikel. php?ID=332735 [Accessed 19 November 2014].

Address for correspondence: Dr O Oleribe, EFMC Complex, Plot 5E Excellence and Friends Street, Dutse Abuja, Nigeria; PO Box 8179 Wuse, Abuja, Nigeria.

Email: obinna.oleribe@expertmanagers.org 